\title{
国国pubvet
}

https://doi.org/10.31533/pubvet.v14n2a510.1-4

\section{Mucocele da vesícula biliar em canino}

\author{
Érika Andrade ${ }^{\oplus}$, Leandro Gois de Almeida ${ }^{\circ}$, Kimberli de Oliveira Duarte ${ }^{2 *}$, Bruna Bertin \\ Fenner $^{30}$, Luciana Lígia Guidolin ${ }^{4}$ \\ ${ }^{l}$ Pós-graduando em clínica médica e cirúrgica pela Qualittas. Caxias do Sul-RS, Brasil. \\ ${ }^{2}$ Estudante de graduação em medicina veterinária, Universidade de Caxias do Sul. Caxias do Sul - RS, Brasil. \\ ${ }^{3}$ Pós-graduanda em clínica médica e cirúrgica de pequenos animais, pela Universidade de Caxias do Sul. Caxias do Sul - RS, Brasil. \\ ${ }^{4}$ Proprietária na clínica veterinária Luciana Guidolin. Caxias do Sul-RS, Brasil. \\ *Autor para correspondência, E-mail: kimberli.duarte@gmail.com
}

Resumo. A mucocele da vesícula biliar é uma das causas de obstrução biliar extra-hepática que causa alteração do fluxo normal da bile e leva a uma série de alterações sistêmicas. $\mathrm{O}$ exame ultrassonográfico é de suma importância para o seu diagnóstico e precocidade no início do tratamento. Foi realizado o atendimento de uma canina, poodle, 13 anos, na Clínica Veterinária Luciana Guidolin, em Caxias do Sul (RS). A paciente apresentava desidratação, apatia e dor a palpação. O hemograma demonstrou leucocitose, as enzimas hepáticas ALT e FA apresentaram valores de $706 \mathrm{mg} / \mathrm{dL}$ e $1620 \mathrm{mg} / \mathrm{dL}$, respectivamente. O exame ultrassonográfico apresentou imagem compatível com mucocele, com possibilidade de ruptura ou ruptura iminente da vesícula biliar. Com base nessa informação foi realizada a colecistomia. No quinto dia de internação houve piora no quadro clínico, e a tutora decidiu pela eutanásia. Após a necropsia, com os achados histológicos obteve-se o diagnóstico de ruptura hepática e peritonite fibrinosa.

Palavras chave: canino, mucocele, gastroenterologia

\section{Gallbladder mucocele in canine}

Abstract. Gallbladder mucocele is one of the causes of extrahepatic biliary obstruction that causes abnormal bile flow and leads to a number of systemic changes. The ultrasound examination is extremely important for its diagnosis and early onset of treatment. A 13year-old poodle canine was treated at the Luciana Guidolin Veterinary Clinic in Caxias do Sul (RS). The patient had dehydration, apathy and pain on palpation. The blood count showed leukocytosis, the liver enzymes ALT and ALP presented values of $706 \mathrm{mg} / \mathrm{dL}$ and $1620 \mathrm{mg} / \mathrm{dL}$, respectively. The ultrasound examination showed an image compatible with mucocele, with the possibility of rupture or imminent rupture of the gallbladder. Based on this information, cholecystomy was performed. On the fifth day of hospitalization, the clinical condition worsened, and the tutor decided to euthanize. After necropsy, histological findings led to the diagnosis of hepatic rupture and fibrin peritonitis.

Keywords: canine, mucocele, gastroenterology

\section{Mucocele en la vesícula biliar de un perro}

Resumen. El mucocele en la vesícula biliar es una de las causas de obstrucción biliar extrahepática que causa un flujo biliar anormal y conduce a una serie de cambios sistémicos. El examen de ultrasonido es extremadamente importante para su diagnóstico y el inicio temprano del tratamiento. Un canino de 13 años fue atendido en la Clínica Veterinaria Luciana Guidolin en Caxias do Sul (RS). El paciente tenía deshidratación, apatía y dolor a la palpación. El recuento sanguíneo mostró leucocitosis, las enzimas 
hepáticas ALT y FA presentaron valores de $706 \mathrm{mg} / \mathrm{dL}$ y $1620 \mathrm{mg} / \mathrm{dL}$, respectivamente. El examen de ultrasonido mostró una imagen compatible con mucocele, con la posibilidad de ruptura o ruptura inminente de la vesícula biliar. En base a esta información, se realizó una colecistomía. Al quinto día de hospitalización, el estado clínico empeoró y el tutor decidió sacrificarlo. Después de la necropsia, los hallazgos histológicos condujeron al diagnóstico de ruptura hepática y peritonitis por fibrina.

Palabras clave: canino, mucocele, gastroenterología

\section{Introdução}

As obstruções biliares extra-hepáticas ocorrem quando há alteração no fluxo normal da bile, devido a diversas causas. Uma mucocele da vesícula biliar ocorre devido à combinação de hiperplasia do epitélio associada à disfunção das células muco secretoras dentro da mucosa (Cogliati et al., 2015; Radlinsky, 2015). O conteúdo torna-se tão espesso que não pode ser excretado para fora do canal biliar (Radlinsky, 2015). Sua expansão progressiva causa necrose isquêmica, ruptura, peritonite biliar e infecções oportunistas (Cogliati et al., 2015). Os cães acometidos são de meia-idade a idosos e não há predileção sexual (Fraser et al., 1996; Watson \& Bunch, 2015). Os sinais clínicos variam, como anorexia, êmese, letargia. Icterícia pode estar presente. O cão pode apresentar dor ou distensão abdominal, se houver ruptura da vesícula biliar. Nos exames laboratoriais, as alterações observadas podem ser de leucocitose por neutrofilia e aumento da atividade sérica das enzimas hepáticas, principalmente fosfatase alcalina (FA) e $\gamma$-glutamiltransferase (GGT) (Cogliati et al., 2015; Watson \& Bunch, 2015).

O diagnóstico pode ser feito pela ultrassonografia abdominal (Kealy et al., 2012). No tratamento conservador pode-se utilizar o ácido ursodesoxicólico, que melhora o escoamento de bile intra-hepática e têm ação imunomoduladora nos processos inflamatórios (Andrade, 2008), S-adenosil-L-metionina, melhorando a secreção biliar (Booth \& McDonaldo, 1992) e agentes antimicrobianos. No tratamento cirúrgico, a técnica de escolha é a colecistectomia (Gomez et al., 2016).

\section{Descrição do caso}

Foi atendida na clínica uma canina, Poodle, castrada, de 13 anos de idade, pesando 5,3 kg. Na anamnese, a tutora queixou-se que a paciente estava com êmese e diarreia, e indicou que o animal não era vacinado. No exame clínico foi obtido a temperatura retal de $39,3^{\circ} \mathrm{C}$, as mucosas estavam normocoradas, tempo de perfusão capilar (TPC) de dois segundos, evidenciou-se desidratação, apatia e dor a palpação abdominal. O hemograma demonstrou leucocitose, as enzimas hepáticas alanina transaminase (ALT) no valor de $706 \mathrm{mg} / \mathrm{dL}$ (valores de referência $21-86 \mathrm{mg} / \mathrm{dL}$ ) e FA no valor de 1.620 $\mathrm{mg} / \mathrm{dL}$ (valores de referência $20-156 \mathrm{mg} / \mathrm{dL}$ ). O soro estava ictérico. A paciente foi internada com uma taxa de fluidoterapia de $31 \mathrm{~mL} /$ hora na bomba de infusão com ringer lactato. A terapia medicamentosa iniciou-se com ceftriaxona (30 mg/kg, IV), citrato de maropitant ( $1 \mathrm{mg} / \mathrm{kg}, \mathrm{SC})$, dipirona $(25 \mathrm{mg} / \mathrm{kg}$, $\mathrm{SC})$, metadona $(0,2 \mathrm{mg} / \mathrm{kg}, \mathrm{SC})$, metronidazol $(20 \mathrm{mg} / \mathrm{kg}$, IV), omeprazol $(0,7 \mathrm{mg} / \mathrm{kg}$, IV) e raniditina $(2 \mathrm{mg} / \mathrm{kg}, \mathrm{SC})$.

No exame ultrassonográfico apontou hepatomegalia discreta, com o parênquima hepático hipoecogênico homogêneo. Destaque para a vesícula biliar acentuadamente distendida, repleta por conteúdo amorfo hiperecogênico, imóvel, sem vascularização do Doppler. Sendo a imagem compatível com mucocele. A vesícula mediu em torno de $5,5 \mathrm{~cm}$ x $3,85 \mathrm{~cm}$, com paredes não delimitadas. $\mathrm{O}$ mesentério apresentou-se hiperecogênico em abdômen cranial, principalmente adjacente à vesícula biliar, sendo observado discreta quantidade de líquido livre. O laudo realçou nas observações a possibilidade de ruptura ou ruptura iminente da vesícula biliar, sugerindo laparotomia exploratória. Diante dos sinais clínicos apresentados pela paciente com os resultados dos exames complementares, a conduta de tratamento escolhida foi a cirúrgica.

Na sala cirúrgica, ocorreu indução à anestesia com propofol ( $5 \mathrm{mg} / \mathrm{kg}$, IV). A técnica anestésica escolhida foi a Anestesia Total Intravenosa (TIVA) com infusão de propofol $(0,5 \mathrm{mg} / \mathrm{kg} / \mathrm{min})$ utilizando bomba de seringa em associação à infusão contínua do protocolo DexFLK, dexmedetomidina $(0,05 \mathrm{mg} / \mathrm{Kg} / \mathrm{min})$, fentanil ( $0,03 \mu \mathrm{g} / \mathrm{kg} / \mathrm{min})$, lidocaína (50 $\mu \mathrm{g} / \mathrm{kg} / \mathrm{min})$ e cetamina $(10 \mu \mathrm{g} / \mathrm{kg} / \mathrm{min})$ usando bomba de infusão. 
Após o acesso a cavidade abdominal verificou-se líquido livre e peritonite. Localizando a vesícula biliar, foi constatado que não havia rompimento, porém a vesícula estava com aumento de volume e o conteúdo biliar na palpação mostrava-se espesso. Após a incisão da vesícula biliar, observou-se um conteúdo mucoso e espesso. Foi optado pela retirada do conteúdo e síntese da vesícula. Uma amostra de bile foi colhida para cultura, o resultado foi negativo para crescimento bacteriano em meio enriquecido seletivo. Após, sucedeuse a lavagem da cavidade abdominal com solução salina estéril aquecida Nacl 0,9\%. Durante o fechamento da cavidade foi implantando um dreno na parte cranial do abdômen.

No dia seguinte o dreno foi retirado. Sucedidos dias da recuperação pós-operatória a paciente estava com anorexia e foi decidido a colocação de sonda esofágica pela técnica de esofagostomia. No quinto dia, começou a apresentar dificuldades respiratórias e muitas náuseas. Na mesma tarde a proprietária decidiu pela eutanásia.

No exame de necropsia, foi observado na abertura da cavidade abdominal discreto exsudato de coloração alaranjada com hiperemia de omento e serosa intestinal. A vesícula biliar estava com aderência do omento, ligada por pontos cirúrgicos e sem ruptura. Foi observado ruptura do lobo subjacente à vesícula biliar que apresentava comunicação interna com a vesícula biliar. A análise histológica identificou espessamento da vesícula biliar, fibrina e deposição de tecido conjuntivo fibroso. No fígado observou-se colestase multifocal moderada. Na área de ruptura hepática foi identificada necrose, hemorragia, fibrina, trombose e infiltrado inflamatório formado de neutrófilos, plasmócitos e linfócitos. Peritonite foi confirmada pela observação de infiltrado inflamatório na cápsula de Glisson e na serosa intestinal. Com os achados histológicos obteve-se o diagnóstico de ruptura hepática e peritonite fibrinosa.

\section{Discussão}

As doenças do sistema hepático são muito comuns na rotina da clínica de cães e gatos, normalmente são secundárias a alterações metabólicas. A etiologia e patogênese da mucocele na vesícula biliar é controversa. A hiperplasia da mucosa cística está presente na maioria dos casos (Aguirre et al., 2007). No caso em questão, não foi possível determinar a etiologia; porém, a ocorrência de hiperplasia cística da mucosa da vesícula biliar não pode ser descartada como fator da mucocele. Cães adultos maduros e com sinais gastrointestinais são predispostos a distúrbios da vesícula biliar. A faixa etária observada e os sinais de êmese e diarreia estão de acordo com a literatura (Aguirre et al., 2007; Worley et al., 2004). O fator racial não está associado; porém, algumas raças são predispostas (Kahn et al., 2013). Os sinais clínicos demonstrados foram de desidratação, dor abdominal e apatia (Cogliati et al., 2015; Watson \& Bunch, 2015; Worley et al., 2004). A icterícia não foi observada, pois a bilirrubina quando cai na cavidade abdominal não é absorvida. O soro ictérico indicou colestase, como resultado da obstrução biliar pela mucocele.

As imagens ultrassonográficas da vesícula distendida com conteúdo amorfo hiperecogênico foram compatíveis com mucocele (Garcia et al., 2015; Kealy et al., 2012). Neste exame, também foi observado líquido livre. Correlacionando o líquido abdominal e a leucocitose apontou-se para a possibilidade de ruptura da vesícula biliar e peritonite biliar (Crews et al., 2009; Pike et al., 2004). A sensibilidade da ultrassonografia para detecção de ruptura é de $85,7 \%$ (Pike et al., 2004).

A colicistectomia é a técnica de eleição em casos de mucocele da vesícula biliar, devido ao potencial de rompimento da vesícula e as recidivas (Cogliati et al., 2015; Watson \& Bunch, 2015; Worley et al., 2004). Há uma alta mortalidade perioperatória, cerca de $21 \%$ no estudo de Pike et al. (2004). Entretanto os que sobrevivem a este período possuem um bom prognóstico (Watson \& Bunch, 2015).

Tem sido referido para a possibilidade de infecções bacterianas e processos inflamatórios colaborarem para a doença (Besso et al., 2000; Romero et al., 2008; Watson \& Bunch, 2015). Contudo, o conteúdo biliar da canina foi encaminhado para cultura, o qual apresentou resultado negativo. Complicações foram observadas no caso apresentado, observou-se a necrose isquêmica hepática e a peritonite biliar. Outra complicação foi a ruptura hepática adjacente, porém não há relatos na literatura.

\section{Conclusão}

A mucocele da vesícula biliar deve ser considerada como diagnóstico clínico diferencial de qualquer doença hepatobiliar, na qual os sinais clínicos e os exames laboratoriais indiquem uma colestase. Desta 
forma, se torna importante a realização de exame ultrassonográfico, pois esta é uma das ferramentas mais valiosas para o diagnóstico da mucocele da vesícula biliar. A observação de complicações da mucocele são fatores determinantes no prognóstico.

\section{Referências bibliográficas}

Aguirre, A. L., Center, S. A., Randolph, J. F., Yeager, A. E., Keegan, A. M., Harvey, H. J. \& Erb, H. N. (2007). Gallbladder disease in Shetland Sheepdogs: 38 cases (1995-2005). Journal of the American Veterinary Medical Association, 231(1):79-88.

Andrade, S. F. (2008). Manual da Terapêutica Veterinária. São Paulo: Rocca.

Besso, J. G., Wrigley, R. H., Gliatto, J. M. \& Webster, C. R. L. (2000). Ultrasonographic appearance and clinical findings in 14 dogs with gallbladder mucocele. Veterinary Radiology \& Ultrasound, 41(3):261-271.

Booth, N. H. \& McDonaldo, L. E. (1992). Farmacologia e terapêutica em veterinária. Rio de Janeiro, Brasil: Guanabara Koogan.

Cogliati, B., Silva, R. D. \& Ushikoshi, W. S. (2015). Doenças hepáticas caninas. In M. M. Jerico, J. P. Andrade Neto \& M. M. Kogika (Eds.), Tratado de medicina interna de cães e gatos. Rio de Janeiro: Roca, vol.1 v. p. 1035-1043. (Vol. 1, pp. 1035-1043). Rio de Janeiro, Brasil: Roca.

Crews, L. J., Feeney, D. A., Jessen, C. R., Rose, N. D. \& Matise, I. (2009). Clinical, ultrasonographic, and laboratory findings associated with gallbladder disease and rupture in dogs: 45 cases (19972007). Journal of the American Veterinary Medical Association, 234(3):359-366.

Fraser, C. M., Bergeron, J. A., Mays, A. \& Aiello, S. A. (1996). Manual Merck de Veterinária: um manual de diagnóstico, tratamento, prevenção e controle de doenças para o veterinário: Roca.

Garcia, D. A. A., Froes, T. R. \& Feliciano, M. A. R. (2015). Fígado. In M. A. R. Feliciano, J. C. Canola \& W. R. R. Vicente (Eds.), Diagnóstico por imagem em cães e gatos (pp. 549-577). São Paulo, Brasil: MedVet.

Gomez, J. R., Sanudo, M. J. M. \& Morales, J. G. (2016). Fígado. In J. R. Gomez, M. J. M. Sanudo \& J. G. Morales (Eds.), Cirurgia na clínica de pequenos animais: Abdome cranial (pp. 199-241). São Paulo, Brasil: MedVet.

Kahn, S. A., Mullin, C. M., Lorimier, L.-P., Burgess, K. E., Risbon, R. E., Fred III, R. M., . . Clifford, C. A. (2013). Doxorubicin and deracoxib adjuvant therapy for canine splenic hemangiosarcoma: a pilot study. The Canadian Veterinary Journal, 54(3):237.

Kealy, J. K., McAllister, H. \& Graham, J. P. (2012). Radiologia e Ultrassonografia do Cão e do Gato (Vol. 1). São Paulo: Manole.

Pike, F. S., Berg, J., King, N. W., Penninck, D. G. \& Webster, C. R. (2004). Gallbladder mucocele in dogs: 30 cases (2000-2002). Journal of the American Veterinary Medical Association, 224(10):16151622.

Radlinsky, M. G. (2015). Cirurgia do sistema biliar extra-hepático. In T. W. Fossum (Ed.), Cirurgia de pequenos animais (pp. 476-487). São Pasulo, Brasil: Elsevier.

Romero, G. M., Ortuño, L. E. G., Casas, F. C., Carvajal, K. S. \& Aguilar, R. E. M. (2008). Mucocele en la vesícula biliar de un perro: hallazgos clínico-patológicos. Veterinaria México, 39(3):335-340.

Watson, P. J. \& Bunch, S. E. (2015). Doenças hepatobiliares no cão. In R. W. Nelson \& C. G. Couto (Eds.), Medicina Interna de Pequenos Animais (Vol. 1, pp. 556-557). Rio de Janeiro: Elsevier.

Worley, D. R., Hottinger, H. A. \& Lawrence, H. J. (2004). Surgical management of gallbladder mucoceles in dogs: 22 cases (1999-2003). Journal of the American Veterinary Medical Association, 225(9):1418-1422.

Recebido: 19 de outubro, 2019.

Aprovado: 25 de novembro, 2019.

Publicado: 13 de março, 2020.

Licenciamento: Este artigo é publicado na modalidade Acesso Aberto sob a licença Creative Commons Atribuição 4.0 (CC-BY 4.0), a qual permite uso irrestrito, distribuição, reprodução em qualquer meio, desde que o autor e a fonte sejam devidamente creditados. 